\title{
Plight of UK science
}

SIR-The leading article on the report of the Advisory Board for the Research Councils (ABRC) on university research (Nature 328, 279; 1987) was, to say the least, inadequate. With friends like this, who needs enemies?

The dull acquiescence of the ABRC to the British government's jaundiced view of the universities in general and basic research in particular is bad enough without Nature weighing in with a bland, powderpuff commentary. Indeed, it is difficult to remember any leading article in Nature over the past few years that has bared any real teeth to the Department of Education and Science. No doubt Nature will soon be telling us again in veiled terms that the abolition of tenure is no bad thing.

So what does the ABRC propose? Answer, exactly what the government wants to hear. A small elite of 'core staff' (no doubt enjoying the emasculated interpretation of tenure that $\mathrm{Mr}$ Kenneth Baker will soon be thinking up) in a small number of research centres that will entertain 'visiting teams' of workers 'seconded' from their home institutions. This exercise in reality amounts to no more than moving around the remaining bits of furniture at maximal inconvenience for a minimum of benefit. If the ABRC, and Nature for that matter, thinks that this dog's dinner of ideas will bring expatriates rushing back from the United States and elsewhere and encourage postdocs to linger a little while longer in basic research, they are whistling in the wind. It is time for those with influence and authority in our scientific community to stop doing the government's dirty work and to say loud and clear 'enough is enough'.

The truth is that science has surrendered to mammon. The government has no patience with anything that cannot be exploited for profit and basic research is a runt in the government's latest litter of 'radical' proposals. As one report follows another in depressingly similar style, with the usual hackneyed cliches 'economic realities' 'need to rationalize', 'become cost-effective' and so on, one is reminded of the scorn the poor bloody infantry in the First World War had for the generals safely back at headquarters. With the notable exception of Denis Noble's Save British Science initiative, our scientific generals have been deafening in their silence. Come on you generals, give your troops the lead they so desperately need otherwise one can only suspect that you are keeping your heads down for a quiet life, and why not? For many, their research careers are over and jolly nice ones they had no doubt, in the decades before this one.

If the government will not listen, those in the scientific establishment must be prepared to rise to the challenge. If they are too tired to fight, then they should be honest enough to make way for others. It would be nice to think that the challenge will be accepted, even at the eleventh hour.

St George's Hospital Medical School,

Cranmer Terrace,

London SW17 ORE,

$U K$

SIR-I have been shocked in recent months by the attitude of leading articles in Nature to the government's plans for science in Britain. It is astonishing how rapidly the focus of this argument has moved in the direction the government wishes. An article containing such proposals as the leading article "World's end or its beginning?" (Nature 328, 279; 1987) would have been amazing only a year ago and provoked a storm of protest whereas now it apparently provokes only restrained agreement.

I believe the whole debate stems from a false premise, which is that British science is a failure. This seems to me to be so far from the truth as to be almost ridiculous. British science is probably second only to that of the United States in terms of both quantity and quality of output (Trends Neurosci. 10, 105; 1987), and this despite a much lower proportional funding. That sounds like a high degree of 'efficiency' to me, especially considering the starvation of funds and low morale of recent years.

It is unfortunate that British science conceded the argument with the government at the very beginning by allowing the accusations of 'inefficiency' and 'failure' to go by default. Once these points were allowed, the present radically destructive policies followed with horrible inevitability.

MRC Neuroendocrinology Unit,

Newcastle General Hospital,

Westgate Road,

Newcastle upon Tyne NE4 6BE, UK

\section{Easier said than done}

SIR-The widespread use of the phrases in vivo and in vitro in the scientific literature is undoubtedly due to the fact that much is said with few words. Moreover, the situations referred to in the two cases are encountered frequently. We propose a new and similar expression that corresponds to a frequent occurrence in the planning of experiments.

The need for such an expression was brought home recently when one of our students commented that her senior thesis had become much more complicated and difficult - when she started carrying out experiments - than it had seemed it should be, based on the planning stages alone; on paper, the idea had appeared simple; in execution, it was much more difficult.

In the belief that this widespread situation can be summed up succinctly, we suggest the phrase describing thought experiments might be in charta, signifying 'on paper' and further, that the contrast might be forcefully expressed in charta facile, in vitro difficile - that planning something is often easier than carrying it out. The phrase sums up much of the frustrations of research.

C. Tyler Burt

Laboratory of Molecular Biophysics,

National Institute of

Environmental Health Sciences, PO Box 12233 ,

Research Triangle Park, North Carolina 27709, USA

JOHN HANCOCK Frederic Peachy

Reed College,

Portland,

Oregon 97202, USA

\section{King Faisal prizes}

SIR-The article about the 1987 King Faisal International Prizes (Nature 326, $118 ; 1987)$ leads with the curious allegation that the history of the prizes has been "somewhat shaky". The independent scholars who control the jury process have occasionally decided that none of the submitted nominations in the designated topic for a particular year really meets the foundation's stringent qualifications. Rather than perceiving that as "shaky", one might take the view that the foundation and the scientists involved in the prize selection process are attempting to maintain the quality and selectivity that the foundation has attempted to build over the past decade.

At the end of the article an inference is made that our selection process has been prejudiced on the matter of sex, religion and race. We have never taken into account any of these factors because we do not control the jurors, whose members are from every part of the world. Dr Michael Field was the co-winner of the King Faisal International Prize in Medicine in 1984 and, as he has pointed out (Nature 327, 96; 1987), he is Jewish.

We too regret the absence of female winners. As the international jurors consider only the submitted nominations, however, the blame might better be attributed to the many international institutions that actually do the nominating.

BANDAR BIN SAUD BIN KHALID

King Faisal Foundation,

PO Box 352,

Riyadh 11411 ,

Saudi Arabia 